\title{
Optimal Decisions and Financing Strategies Selection of Supply Chain with Capital Constraint
}

\author{
Bo Wang, ${ }^{1,2,3}$ De-Chun Huang, ${ }^{1,3}$ Hai-yan Li, ${ }^{4}$ and Ji-Yong Ding ${ }^{1}$ \\ ${ }^{1}$ School of Business, Hohai University, Nanjing 211100, China \\ ${ }^{2}$ School of Business, Beifang University of Nationalities, Yinchuan 750021, China \\ ${ }^{3}$ Jiangsu Provincial Collaborative Innovation Center of World Water Valley and Water Ecological Civilization, Nanjing 211100, China \\ ${ }^{4}$ College of Mathematics and Information Science, Beifang University of Nationalities, Yinchuan 750021, China
}

Correspondence should be addressed to De-Chun Huang; huangdechun66@163.com

Received 7 January 2016; Accepted 15 June 2016

Academic Editor: Chaudry M. Khalique

Copyright (C) 2016 Bo Wang et al. This is an open access article distributed under the Creative Commons Attribution License, which permits unrestricted use, distribution, and reproduction in any medium, provided the original work is properly cited.

\begin{abstract}
Two financing modes can be considered for manufacturer's production capital constrained: RPFM (retailer's prepayment financing mode) and PCFM (procurement contract financing mode). Under the RPFM, the retailer places order in advance for a discount price and makes prepayment; manufacturer is able to finance from a bank as production quantity cannot satisfy the secondorder quantity of retailer. By contrast, manufacturers make financing from commercial banks based on the procurement contract with upstream supplier under the PCFM. Taking into account the relation between production volumes with the manufacturer's own capital and retailer's order quantity, the optimal production and financing decision model for manufacturer under these two financing modes are built. Moreover, the profits of the manufacturer, the retailer, and the supply chain are compared and discussed. Results show that both of the two modes can create new value and profit for the supply chain with capital constraint and achieve optimal production under "newsvendor" mode; the supply chain has the better performance under the RPFM than that achieved under the PCFM. Also, under the RPFM, the manufacturer's production and the profit of the whole supply chain would be increased when the manufacturer makes the second financing. Similar conclusion is reached under the PCFM. Finally, numerical study was given to demonstrate the conclusions.
\end{abstract}

\section{Introduction}

A manufacturer with capital constraint restricts its own production capacity and fails to meet retailer's order demands. For manufacturer with capital constraint, there are two financing modes commonly used: retailer' prepayment and manufacturer's financing from commercial banks. Two factors make the retailer be willing to provide working capital to the manufacturer. On the one hand, it stabilizes purchasing channel, ensures goods source quality, and maintains the long-term cooperation relationship with the enterprises; on the other hand, the retailer can get some discount from the manufacturer. With regard to the manufacturer, by selecting retailer's prepayment financing, it gets the needed production capital, ensures smooth selling channel, and gets sales volume in advance. For example, the large retail enterprise, such as Carrefour, Wal-Mart, and Wu-Mart, makes credit rating for upstream manufacturers or suppliers and provides capital support with their own capital. However, the prepayment financing mode is often under the precondition of the manufacturer's discount on the supplied goods, which often reduces profit margin of the manufacturer. Hence, the manufacturer often considers finance from financial institutes, which becomes a preferred way of corporate financing. To avoid credit risk, financial institutes represented by commercial banks often need a third party to provide security or pledge for the loan enterprises. With emerging of the innovative financing service in the supply chain, financing from the bank based on interenterprise relationship becomes a new option for capital-constrained enterprises and a new profit increasing point for commercial banks.

In the field of corporate finance research, owing to the $M \& M$ theory's assumption that corporate investment and financing are independent from production and operation [1], 
capital management in supply chain has long been ignored. However, the factors such as agent cost, information asymmetry, and tax make the capital structure of enterprise be closely related to the production decision [2]. Studies show that capital constraint will impact on enterprise's operation decision, while financing service can create new value to realize optimal decision and achieve the supply chain coordination [3-5].

Supply chain financing mainly focuses on the optimal decision and financing strategy selection under internal and external financing modes. Relying on interenterprise trade relation in the supply chain, the commercial credit mode could satisfy capital demand of enterprises. Commercial credit financing has appellations such as delay payment, trade financing, and postponement strategy [6], which are all regarded as short-term financing methods. When the buyer is capital constrained, upstream manufacturer or supplier may provide credit financing by this financing mode. Studies show that commercial credit financing could stimulate the retailers' order and expand market share for suppliers and is an important financing method for the buyer $[7,8]$. Studies on commercial credit mode mainly include optimal decision about credit term [9], order policy [10, 11], and optimal batch size [12]. The above studies mainly focus on downstream retailer with capital constraint and rarely focus on commercial credit financing when manufacturer faces capital constraint. Besides, commercial credit financing is also an important way for supply chain coordination with capital constraint. For example, Lee and Rhee showed that the trade credit contract can better coordinate supply than commercial bank financing where both retailer and manufacturer are capital constrained [13]. Chen and Wang indicated that commercial credit can create value for supply chain and partially coordinate supply chain with capital constrained [14].

External financing via interenterprise relation is another important way for capital-constrained supply chain. In the production phase from cash payment to product selling, the enterprise may get credit from external financial institute with inventory pledge or warehouse receipt pledge. For example, Buzacott and Zhang connected asset financing to production decision and built model with available cash as assets and liabilities; meanwhile, outstanding loans under different interest rates were taken into account [15]. The study indicated the importance of simultaneously considering production and financing strategies. Under financing mode with pledge by warehouse receipts and taking into account the bankrupt risk of retailer, Yan and Sun studied optimal credit decision of commercial bank, optimal wholesale price of manufacturer, and optimal order quality of retailer [16]. Yan and Sun make a comparison between two different limited financing modes where retailer is capital constrained and consider the bankruptcy risk; the results have shown that the two financing modes all can improve the expected profits of supply chain [17].

In addition, enterprise can get guarantee based on the cooperation relation between upstream and downstream enterprises, so as to finance from commercial bank. For example, Yi and Zhou considered the decision of inventory pledge financing from commercial bank under core enterprise's buy-back [18]. Zhang and Tang considered the supply chain financing decision of financing from commercial bank under manufacturer's guarantee where retailer is capital constrained and made decision for optimal order quantity of retailer and optimal order price of manufacturer [19]. Moreover, financing from commercial bank with procurement relation between upstream and downstream enterprises raises more and more academic concern recently. Downstream enterprise requests credit loan towards commercial bank and the latter checks the trade relation between upstream and downstream enterprises. Then, when downstream enterprise pays cash deposit in certain rate, the commercial bank will pay for the raw materials purchased for upstream enterprise, and the upstream enterprise should store such raw materials in warehouse specified by the commercial bank. At last, commercial bank gets back the capital by controlling downstream enterprise's right of taking delivery of goods. The related studies refer to [20, 21].

For supply chain enterprise facing capital constraint, different research on the question of which financial methods should be adopted has different conclusions. Zhou and Groenevelt compared trade financing and bank financing from perspective of asset pledge. They draw a conclusion that commercial bank credit is more attractive than trade credit [22]. Jing et al. indicate that, as higher wholesale price is required, commercial bank financing is superior to commercial credit financing. When the production cost is low, commercial credit financing can uniquely achieve equilibrium [23]. However, according to the information superiority theory, supplier can collect normal business information of retailer more easily than the bank in credit loan. In case of default of the retailer, the supplier can take the advantage of disposing products; meanwhile, choosing credit loan represents confidence of the supplier in its products, which could facilitate control on trade relation of the supply chain [24]. In addition, Caldentey and Chen indicate that, for the retailer, internal financing from supplier is superior to external financing from commercial bank [25]. Kouvelis and Zhao indicated that manufacturer can improve profit of supply chain by selecting commercial credit financing and retailer financing from manufacturer better than from commercial bank [26]. Chen made a comparison between commercial credit financing and bank financing and pointed out that commercial credit financing can uniquely achieve equilibrium [27]. Yan et al. designed a partial trade credit guarantee contract for the coordination of supply chain finance (SCF) system where the retailer is capital constrained [28]. The results have shown that this contract can realize profit maximization of supply chain and achieve the coordination and financing equilibrium for SCF system based on a suitable guarantee coefficient.

Current studies on supply chain financing are mainly based on the assumption of buyer's capital constraint and mainly focus on these issues: optimal order quantity, retailer's order strategy, and the financing decision and coordination under these two financing modes. Rare studies focus on optimal decision and financing strategy selection of manufacturer under capital constraint. Wang et al. establish a conditional and partial trade credit model, where the supplier 
is capital constrained and as the leader in the Stackelberg model [29]. This model makes the supply chain more stable and a win-win outcome can be realized and the supplier's financial pressure can be relieved. Under the condition that manufacturer specifies quantity discount rate, Zeng and Luo designed trade credit incentive mechanism for retailer to make prepayment to the manufacturer and studied inventory management and coordination of supply chain. They reached the conclusion that, if the manufacturer got high profit, the mechanism could achieve coordination of the entire supply chain and Pareto Optimality [30]. In addition, Wang and Luo studied the optimal production decision and financing strategy selection of manufacturer under two financing modes, retailer's prepayment financing model (RPFM) and supplier's commercial bank loan under retailer's guarantee, when supplier faced capital constraint. The result indicates that the two financing modes can both realize optimal production under noncapital constraint; moreover, when retailer cost is lower than bank loan interest, retailer's prepayment financing mode should be selected; otherwise, commercial bank financing under retailer's guarantee should be adopted [31]. Zhan et al. made a comparison and analyzed manufacturer's production decision and retailer's financing problem under the RPFM and commercial bank financing, which further considered the price discount for retailer's prepayment. The result shows that both modes could create value for supply chain, and prepayment financing could be better than financing from bank when interest rate is specified and price discount rate meets certain requirements [32]. In addition, Xiao and Luo made a further research of dual-channel supply chain and get the similar results that the retailer's prepayment financing mode (RPFM) is better than financing from bank when manufacturer is capital constrained under the condition that the discount rate is equal to the bank rate [33].

References [31,32] are most closely related to this study. However, the difference is that, in the above literatures, further discussion is needed on the problem whether manufacturer's own capital could satisfy order demand of retailer or no. In addition, with the RPFM, in case of secondary order from retailer, the manufacturer needs to make secondary financing from commercial bank for further production. In this case, how could the manufacturer select financing strategy and how to make optimal production? Aiming at the problem, under procurement contract financing mode (PCFM), the question of whether the manufacturer's own capital could satisfy retailer's order is discussed. Furthermore, we studied the optimal production and financing strategy of manufacturer and made a comparison analysis on supply chain performances between RPFM and PCFM.

The remainder of this paper is organized as follows. Section 2 describes the studied problem and symbols involved in modeling and illustrates assumptions and basic models in the paper. Sections 3 and 4 present supply chain financing decision models under RPFM and under RPFM, respectively. Section 5 compares the supply chain performances under these two financing modes; Section 6 presents a numerical example. The last section is the conclusion.

\section{Problem Description and Basic Model}

2.1. Problem Description and Notations. In the supply chain system constituted by a single supplier, manufacturer, and the retailer, the upstream supplier and downstream retailer have commercial credit and stable operational cash flow. The manufacturer purchases raw materials from a supplier to produce certain products and sells to the retailer who faces uncertain demands. It is assumed that, during the entire procurement, manufacturing, and selling processes, the manufacturer is required to solve the capital constraint through financing.

In case of capital constraint, the manufacturer should determine production after receiving an order request from the retailer. And its own capital may be insufficient to cover the procurement cost for the order quantity. The problems to be considered by the manufacturer during financing decision-making are as follows. Under the precondition of ordering a certain quantity of products with wholesale price discount, the retailer may make prepayment. However, in case of secondary order when the sales volume exceeds order quantity, the retailer will no longer enjoy a price discount. Moreover, if its own capital is insufficient for secondary production, the manufacturer needs to make the secondary financing. In this case, the manufacturer may rely on the procurement contract with upstream supplier and get credit loan from the bank. We called this mode as retailer's prepayment financing mode (RPFM).

In addition, the manufacturer could get credit loan directly from commercial bank through procurement contract with upstream suppler and should pay initial deposit to the bank in certain ratio; then, after check procurement contract between supplier and manufacturer, the bank provides loan in certain interest rate for payment of the capital needed by manufacturer in production. Besides, the manufacturer should store the raw materials in logistics enterprise specified by a commercial bank, while the bank will control the capital recycling through the right of taking delivery of goods. We called this mode as procurement contract financing mode (PCFM). Figure 1 demonstrates the specific frame and flow.

In this paper, notations and symbols are shown in Notations.

\subsection{Assumptions and Basic Model}

Assumption 1. The supplier, manufacturer, and retailer are all risk-neutral and have perfect rationality.

Assumption 2. The information among supplier, manufacturer, and retailer is symmetrical with no information concealment.

Assumption 3. The product residual value is zero and reputation loss caused by stockout is not taken into account.

Assumption 4. The supplier, manufacturer, and retailer all comply with the laws in operation and financing and no one breaks the contract.

Assumption 5. The manufacturer just has only financing chance when the retailer is reordering under RPFM. 


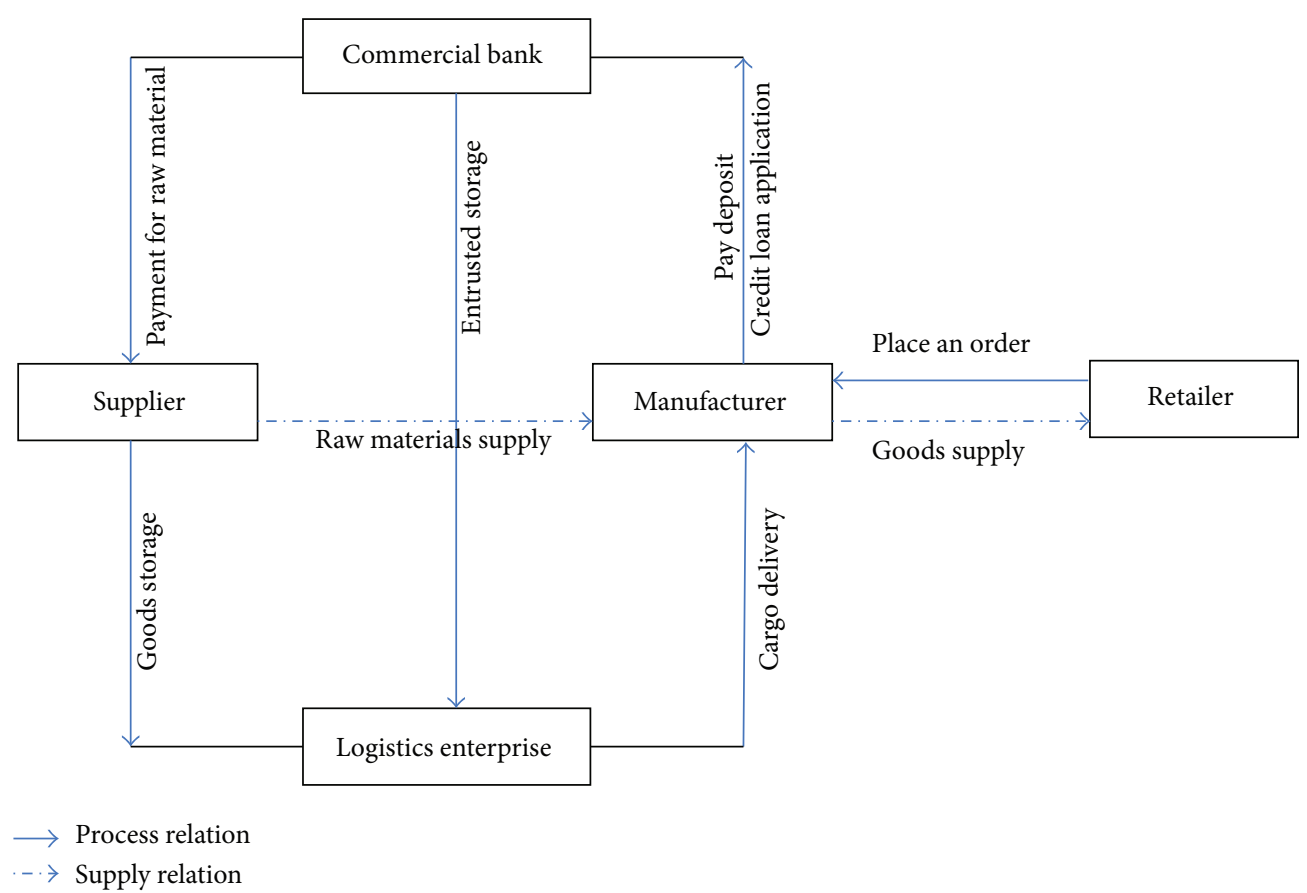

Figure 1: Frame and flows of the PCFM.

Without capital constraint, the manufacturer's production $Q_{N}$ satisfies the retailers order demand. It means that retailer's order complies with the "newsvendor" mode [32]. Expected profits of retailer, manufacturer, and supply chain are

$$
\begin{aligned}
E\left(\pi_{R}^{N}\right)= & (p-w) Q_{N}-p \int_{0}^{Q_{N}}\left(Q_{N}-x\right) f(x) d x \\
& -s \int_{Q_{N}}^{+\infty}\left(x-Q_{N}\right) f(x) d x \\
= & (p-w) Q_{N}-p \int_{0}^{Q_{N}} F(x) d x \\
& -s \int_{Q_{N}}^{+\infty}\left(x-Q_{N}\right) f(x) d x, \\
E\left(\pi_{M}^{N}\right)= & (\omega-c) Q_{N}, \\
E\left(\pi_{T}^{N}\right)= & (p-c) Q_{N}-p \int_{0}^{Q_{N}}\left(Q_{N}-x\right) f(x) d x \\
& -s \int_{Q_{N}}^{+\infty}\left(x-Q_{N}\right) f(x) d x \\
= & (p-c) Q_{N}-p \int_{0}^{Q_{N}} F(x) d x \\
& -s \int_{Q_{N}}^{+\infty}\left(x-Q_{N}\right) f(x) d x .
\end{aligned}
$$

When the manufacturer is capital constrained, and order demand of retailer exceeds the maximum production of manufacturer with its own capital (i.e., $Q_{N}>Q_{0}=B / c$ ), expected profits of retailer, manufacturer, and the whole supply chain are

$$
\begin{aligned}
E\left(\pi_{R}^{C}\right)= & (p-w) Q_{0}-p \int_{0}^{Q_{0}} F(x) d x \\
& -s \int_{Q_{0}}^{+\infty}\left(x-Q_{0}\right) f(x) d x, \\
E\left(\pi_{M}^{C}\right)= & (\omega-c) Q_{0}, \\
E\left(\pi_{T}^{C}\right)= & (p-c) Q_{0}-p \int_{0}^{Q_{0}} F(x) d x \\
& -s \int_{Q_{0}}^{+\infty}\left(x-Q_{0}\right) f(x) d x .
\end{aligned}
$$

Obviously, as $Q_{N}>Q_{0}$, capital constraint results in failure of manufacturer in satisfying the retailer's optimal order and making retailer, manufacturer, and the whole supply chain be incapable of realizing optimal profits under "newsvendor" model.

\section{Supply Chain Financing Decision under RPFM}

3.1. Manufacturer's Profit and Decision. Under the RPFM, the retailer and manufacturer share market demand information. The financing and production decision sequence is as follows. The retailer determines order quantity $q_{B}$ and makes payment for $\alpha \omega q_{B}$; in case of secondary order of retailer, for $q_{B}<$ $X \leq Q_{\max }$ (wherein, $Q_{\max }=B / c+q_{B}$ ), the manufacturer's capital satisfies second-order demand, and the manufacturer cannot need financing; for $Q_{\max } \leq X \leq Q_{1}$, the manufacturer considers secondary financing for production; for $Q_{1} \leq X$, 
which means market demand exceeds production of manufacturer, the production is $Q_{1}$.

(1) For $X<q_{B} \leq Q_{1}$, the prepayment could be sufficient for the manufacturer to meet retailer's demand, and manufacturer's profit is written as $\pi_{M}^{1}=\alpha \omega q_{B}-c Q_{1}$.

(2) For $q_{B}<X \leq Q_{\max }$, the manufacturer satisfies the secondary order demand with its own capital and does not need secondary financing, and manufacturer's profit is $\pi_{M}^{1}=$ $\alpha \omega q_{B}+\omega\left(X-q_{B}\right)-c Q_{1}$.

(3) For $Q_{\max }<X \leq Q_{1}$, the manufacturer's own capital could not satisfy the secondary order demand and will need secondary financing. In this case, initial deposit should be provided to bank in certain rate of total procurement value to be paid to upstream enterprise. $K_{1}$ is the loan amount from bank. After checking procurement contract and relationship, the bank will directly make payment to supplier, where $r$ is loan interest rate. The manufacturer starts secondary production after receiving raw materials needed. And manufacturer's profit is as follows:

$$
\begin{aligned}
\pi_{M}^{1}= & \alpha \omega q_{B}+\omega\left(Q_{\max }-q_{B}\right)+\omega\left(X-Q_{\max }\right) \\
& -K_{1}(1+r)-c Q_{1} .
\end{aligned}
$$

(4) For $Q<X$, the market demand exceeds the maximum production volume of manufacturer after financing. In this case, the manufacturer's profit is $\pi_{M}^{1}=\alpha \omega q_{B}+(\omega-c)(Q-$ $\left.q_{B}\right)-K_{1}(1+r)-c Q_{1}$.

In summary, the profit of manufacturer can be given by

$$
\begin{aligned}
& \pi_{M}^{1} \\
& = \begin{cases}\alpha \omega q_{B}-c Q_{1}, & X<q_{B} \leq Q_{1} \\
\alpha \omega q_{B}+\omega\left(X-q_{B}\right)-c Q_{1}, & q_{B}<X \leq Q_{\max } \\
\alpha \omega q_{B}+\omega\left(X-q_{B}\right)-K_{1}(1+r)-c Q_{1}, & Q_{\max }<X \leq Q_{1} \\
\alpha \omega q_{B}+\omega\left(Q_{1}-q_{B}\right)-K_{1}(1+r)-c Q_{1}, & Q_{1}<X .\end{cases}
\end{aligned}
$$

Therefore, decision model of the manufacturer is given as follows:

$$
\begin{array}{ll}
\max \quad E\left(\pi_{M}^{1}\right) \\
=(\omega-c) Q_{1}+\alpha \omega q_{B}-\omega q_{B} \\
& -K_{1}(1+r)\left[1-F\left(Q_{\max }\right)\right] \\
& -\omega \int_{q_{B}}^{Q_{1}} F(x) d x \\
\text { s.t. } \quad q_{B} \leq Q_{1} \leq \frac{\left(L+B+K_{1}\right)}{c} .
\end{array}
$$

Obviously, we have $\partial^{2} E\left(\pi_{M}^{1}\right) / \partial Q_{1}{ }^{2}=-\omega f\left(Q_{1}\right)<0$, it is easy to observe that Formula (5) is linear constraint, which is nonlinear convex programming with respect to $Q_{1}$, and the manufacturer's optimal production quantity is

$$
\begin{aligned}
& Q_{1}^{*} \\
& = \begin{cases}q_{B}, & F^{-1}\left(1-\frac{c}{\omega}\right)<q_{B} \\
F^{-1}\left(1-\frac{c}{\omega}\right), & q_{B} \leq F^{-1}\left(1-\frac{c}{\omega}\right) \leq Q_{\max } \\
F^{-1}\left(1-\frac{c}{\omega}\right), & Q_{\max } \leq F^{-1}\left(1-\frac{c}{\omega}\right) \leq \frac{\left(L+B+K_{1}\right)}{c} \\
\frac{\left(L+B+K_{1}\right)}{c}, & F^{-1}\left(1-\frac{c}{\omega}\right)>\frac{\left(L+B+K_{1}\right)}{c} .\end{cases}
\end{aligned}
$$

Conclusion 1. When $Q_{\max } \leq F^{-1}(1-c / \omega)$, that is, $c \leq$ $\omega\left(1-F\left(Q_{\max }\right)\right)$, the manufacturer will choose loan from commercial bank. The optimal loan amount is

$$
K_{1}^{*}=c\left(Q^{*}-Q_{\max }\right)= \begin{cases}c\left(F^{-1}\left(1-\frac{c}{\omega}\right)-Q_{\max }\right), & Q_{\max } \leq F^{-1}\left(1-\frac{c}{\omega}\right) \leq \frac{\left(L+B+K_{1}\right)}{c} \\ K_{1}, & F^{-1}\left(1-\frac{c}{\omega}\right)>\frac{\left(L+B+K_{1}\right)}{c} .\end{cases}
$$

3.2. Retailer's Profit and Decision. At the beginning of selling season, the retailer enters into order agreement with the manufacturer, makes prepayment $L$ for the manufacturer to carry out production, and places preorder $q_{B}=L / \alpha \omega$ in discount price; the retailer faces random market demand $X$. For $X<q_{B}$, the retailer should dispose the remaining products by himself and never return them to the manufacturer; for $X \geq q_{B}$, the retailer needs to make the secondary order in price $\omega$ and will no longer enjoy discount. If the market demand exceeds the maximum quantity available in the secondary order, the retailer will bear the loss caused by stockout. Therefore, the final order quantity of retailer is $q_{T}=q_{B}+\left[\min \left(Q_{1}, X\right)-q_{B}\right]^{+}$, and the profit is

$$
\begin{aligned}
& \pi_{R}^{1} \\
& = \begin{cases}p X-L, & X<q_{B} \\
p X-L-\omega\left(X-q_{B}\right), & q_{B} \leq X<Q_{\max } \\
p X-L-\omega\left(X-q_{B}\right), & Q_{\max } \leq X<Q_{1} \\
p Q_{1}-L-\omega\left(Q_{1}-q_{B}\right)-s\left(X-Q_{1}\right), & Q_{1}<X .\end{cases}
\end{aligned}
$$


The retailer's expected profit model is given by

$$
\begin{aligned}
E\left(\pi_{R}^{1}\right)= & p\left(Q_{1}-\int_{0}^{Q_{1}} F(x) d x\right)-\omega\left(Q_{1}-q_{B}\right) \\
& +\omega \int_{q_{B}}^{Q_{1}} F(x) d x-s \int_{Q_{1}}^{+\infty}\left(x-Q_{1}\right) f(x) d x \\
& -L .
\end{aligned}
$$

Substituting (6) into (9), the following can be obtained.

(1) For $Q_{1}^{*}=q_{B}, \partial^{2} E\left(\pi_{R}^{1}\right) / \partial q_{B}{ }^{2}=-(p+s) f\left(q_{B}\right)<0$ holds. From the first-order optimality condition, we have $q_{B}^{*}=F^{-1}(1-\alpha \omega /(p+s))$, where $\alpha \omega^{2}-c(p+s)<0$.

(2) For $Q_{1}^{*}=F^{-1}(1-c / \omega), \partial^{2} E\left(\pi_{R}^{1}\right) / \partial q_{B}{ }^{2}=-\omega f\left(q_{B}\right)<0$ holds. From the first-order optimality condition, $q_{B}^{*}=F^{-1}(1-$ $\alpha)$, where $F^{-1}(1-\alpha)+B / c-F^{-1}(1-c / \omega) \geq 0$.

(3) For $Q_{1}^{*}=F^{-1}(1-c / \omega), \partial^{2} E\left(\pi_{R}^{1}\right) / \partial q_{B}^{2}=-\omega f\left(q_{B}\right)<$ 0 holds. From the first-order optimality condition, we have $q_{B}^{*}=F^{-1}(1-\alpha)$, where

$$
\begin{aligned}
c F^{-1}(1-\alpha)+B & <c F^{-1}\left(1-\frac{c}{\omega}\right) \\
& <\alpha \omega F^{-1}(1-\alpha)+B+K_{1} .
\end{aligned}
$$

(4) For $Q_{1}^{*}=\left(L+B+K_{1}\right) / c$

$$
\begin{aligned}
\frac{\partial^{2} E\left(\pi_{R}^{1}\right)}{\partial q_{B}{ }^{2}}= & -\omega f\left(q_{B}\right) \\
& -\frac{\alpha^{2} \omega^{2}(p-\omega+s)}{c^{2}} f\left(\frac{L+B+K_{1}}{c}\right)<0 .
\end{aligned}
$$

$E\left(\pi_{R}^{1}\right)$ is the convex function of preorder quantity with respect to $q_{B}$. Then, taking the first-order derivative with respect to $q_{B}$, we have

$$
\begin{aligned}
\frac{\partial E\left(\pi_{R}^{1}\right)}{\partial q_{B}}= & \frac{\alpha \omega(p-\omega+s)}{c} \bar{F}\left(\frac{\alpha \omega q_{B}+B+K_{1}}{c}\right) \\
& +\omega \bar{F}\left(q_{B}\right)-\alpha \omega,
\end{aligned}
$$

where $0 \leq q_{B}<(1 / \alpha \omega)\left[c F^{-1}(1-c / \omega)-B-K_{1}\right]$.

Equation (12) is rewritten as

$$
\frac{\partial E\left(\pi_{R}^{1}\right)}{\partial q_{B}}= \begin{cases}\frac{\alpha \omega(p-\omega+s)}{c}\left[1-F\left(\frac{B+K_{1}}{c}\right)\right]+\omega[1-\alpha]>0, & q_{B} \longrightarrow 0 \\ \frac{\alpha(\omega-c)(p-\omega+s)}{c}-\alpha \omega+\omega \bar{F}\left[\frac{c F^{-1}(1-c / \omega)-B-K_{1}}{\alpha \omega}\right], & q_{B} \longrightarrow \frac{\left[c F^{-1}(1-c / \omega)-B-K_{1}\right]}{\alpha \omega} .\end{cases}
$$

If $q_{B}^{*}$ satisfies $\partial E\left(\pi_{R}^{1}\right) / \partial q_{B}=0$, we can deduce

$$
\frac{\partial E\left(\pi_{R}^{1}\right)}{\partial q_{B}}=\frac{\alpha(\omega-c)(p-\omega+s)}{c}
$$

$$
+\omega \bar{F}\left[\frac{c F^{-1}(1-c / \omega)-B-K_{1}}{\alpha \omega}\right]-\alpha \omega
$$

$\leq 0$.

The optimal order quantity $q_{B}^{*}$ is given by

$$
q_{B}^{*}= \begin{cases}F^{-1}\left(1-\frac{\alpha \omega}{p+s}\right), & \alpha \omega^{2}-c(p+s)<0 \\ F^{-1}(1-\alpha), & F^{-1}(1-\alpha)+\frac{B}{c}-F^{-1}\left(1-\frac{c}{\omega}\right) \geq 0 \\ F^{-1}(1-\alpha), & c F^{-1}(1-\alpha)+B<c F^{-1}\left(1-\frac{c}{\omega}\right)<\alpha \omega F^{-1}(1-\alpha)+B+K_{1} \\ \bar{q}, & \frac{\alpha(\omega-c)(p-\omega+s)}{c}+\omega \bar{F}\left[\frac{c F^{-1}(1-c / \omega)-B-K_{1}}{\alpha \omega}\right]-\alpha \omega \leq 0,\end{cases}
$$


where $\bar{q}$ is the positive solution as the following equation:

$$
\begin{aligned}
\frac{\partial E\left(\pi_{R}^{1}\right)}{\partial q_{B}}= & \frac{\alpha \omega(p-\omega+s)}{c} \bar{F}\left(\frac{\alpha \omega q_{B}+B+K_{1}}{c}\right) \\
& +\omega \bar{F}\left(q_{B}\right)-\alpha \omega=0 .
\end{aligned}
$$

Accordingly, substituting (15) into (6) the optimal production volume of manufacturer is rewritten as follows:

$$
Q_{1}^{*}= \begin{cases}F^{-1}\left(1-\frac{\alpha \omega}{p+s}\right), & \alpha \omega^{2}-c(p+s)<0 \\ F^{-1}\left(1-\frac{c}{\omega}\right), & F^{-1}(1-\alpha)+\frac{B}{c}-F^{-1}\left(1-\frac{c}{\omega}\right) \geq 0 \\ F^{-1}\left(1-\frac{c}{\omega}\right), & c F^{-1}(1-\alpha)+B<c F^{-1}\left(1-\frac{c}{\omega}\right)<\alpha \omega F^{-1}(1-\alpha)+B+K_{1} \\ \frac{\left(\alpha \omega \bar{q}+B+K_{1}\right)}{c}, & \frac{\alpha(\omega-c)(p-\omega+s)}{c}+\omega \bar{F}\left[\frac{c F^{-1}(1-c / \omega)-B-K_{1}}{\alpha \omega}\right]-\alpha \omega \leq 0 .\end{cases}
$$

From (15) and (17), the optimal order quantity and production volume are both related to wholesale discount coefficient $\alpha$.

Proposition 1. For IFR distributions of demand, if $q_{B}^{*}=$ $F^{-1}(1-\alpha \omega /(p+s))$ and $q_{B}^{*}=F^{-1}(1-\alpha)$, then we have $d q_{B}^{*} / d \alpha \leq 0$. If $q_{B}^{*}=\bar{q}$, the sufficient condition for $d q_{B}^{*} / d \alpha \leq 0$ is

$$
\begin{aligned}
1 \leq & F\left(\frac{L+B+K_{1}}{c}\right)-\frac{\alpha \omega q_{B}}{c} f\left(\frac{L+B+K_{1}}{c}\right) \\
& -\frac{c}{(p-\omega+s)} .
\end{aligned}
$$

Conversely, if $d q_{B}^{*} / d \alpha \geq 0$

$$
\begin{gathered}
F\left(\frac{L+B+K_{1}}{c}\right)-\frac{\alpha \omega q_{B}}{c} f\left(\frac{L+B+K_{1}}{c}\right) \\
-\frac{c}{(p-\omega+s)}<1,
\end{gathered}
$$

where $\bar{q}$ is the positive solution of (16).

Proof. The following results are obtained from (15).

(1) For $q_{B}^{*}=F^{-1}(1-\alpha \omega /(p+s)), d q_{B}^{*} / d \alpha=-(\omega /(p+$ s) $\left.f\left(F^{-1}(1-\alpha \omega /(p+s))\right)\right)<0$ holds.

(2) For $q_{B}^{*}=F^{-1}(1-\alpha)$, we have $d q_{B}^{*} / d \alpha=-1 / f\left(F^{-1}(1-\right.$ $\alpha))<0$.

(3) For $q_{B}^{*}=\bar{q}$, by taking the first-order derivation of (16) with respect to $\alpha$, we deduce

$$
\frac{d q_{B}^{*}}{d \alpha}=\frac{c \omega(p-\omega+s)\left[1-F\left(\left(L+B+K_{1}\right) / c\right)-\left(\alpha \omega q_{B} / c\right) f\left(\left(L+B+K_{1}\right) / c\right)-c /(p-\omega+s)\right]}{c^{2} \omega f\left(q_{B}\right)+\alpha^{2} \omega^{2}(p-\omega+s) f\left(\left(L+B+K_{1}\right) / c\right)} .
$$

Obviously, if the distribution of demand is IFR, $d q_{B}^{*} / d \alpha \leq$ 0 is equivalent to the following inequality:

$$
\begin{aligned}
1 \leq & F\left(\frac{L+B+K_{1}}{c}\right)-\frac{\alpha \omega q_{B}}{c} f\left(\frac{L+B+K_{1}}{c}\right) \\
& -\frac{c}{(p-\omega+s)} .
\end{aligned}
$$

Conversely, $d q_{B}^{*} / d \alpha \geq 0$; then we have

$$
\begin{aligned}
1> & F\left(\frac{L+B+K_{1}}{c}\right)-\frac{\alpha \omega q_{B}}{c} f\left(\frac{L+B+K_{1}}{c}\right) \\
& -\frac{c}{(p-\omega+s)} .
\end{aligned}
$$


Conclusion 2. From Proposition 1, the optimal order quantity $q_{B}^{*}$ under prepayment is negatively related to the discount rate $\alpha$; that is, larger discount rate value represents smaller discount rate and leads to smaller optimal order quantity $q_{B}^{*}$. On the contrary, smaller discount rate value represents larger discount rate and leads to larger optimal order quantity $q_{B}^{*}$.

Proposition 2. For IFR distributions of demand, if credit loan $K_{1}$ is constant, the retailer's profit $E\left[\pi_{R}^{1}\right]$ is a decreasing function with respect to $\alpha$ and satisfies the following formula:

$$
\frac{\partial E\left[\pi_{R}^{1}\right]}{\partial \alpha}= \begin{cases}-\omega F^{-1}\left(1-\frac{\alpha \omega}{p+s}\right), & Q_{1}^{*}=q_{B}^{*}=F^{-1}\left(1-\frac{\alpha \omega}{p+s}\right) \\ -\omega F^{-1}(1-\alpha), & Q_{1}^{*}=F^{-1}\left(1-\frac{c}{\omega}\right), q_{B}^{*}=F^{-1}(1-\alpha) \\ -\frac{\omega \bar{q}}{\alpha} F(\bar{q}), & Q_{1}^{*}=\frac{\left(\alpha \omega \bar{q}+B+K_{1}\right)}{c}, q_{B}^{*}=\bar{q}\end{cases}
$$

where $\bar{q}$ is the positive solution of (16).

Proof. (1) For $Q_{1}^{*}=q_{B}^{*}=F^{-1}(1-\alpha \omega /(p+s)), \partial \pi_{R}^{1} / \partial \alpha=$ $-\omega F^{-1}(1-\alpha \omega /(p+s))<0$ holds.

(2) For $Q_{1}^{*}=F^{-1}(1-c / \omega), q_{B}^{*}=F^{-1}(1-\alpha), \partial \pi_{R}^{1} / \partial \alpha=$ $-\omega F^{-1}(1-\alpha)<0$ holds.

(3) For $Q_{1}^{*}=\left(\alpha \omega \bar{q}+B+K_{1}\right) / c, q_{B}^{*}=\bar{q}$, we have

$$
\begin{aligned}
\frac{\partial \pi_{R}^{1}}{\partial \alpha} & =\frac{\omega \bar{q}}{c}(p-\omega+s) \bar{F}\left(\frac{\alpha \omega \bar{q}+B+K_{1}}{c}\right)-\omega \bar{q} \\
& =-\frac{\omega \bar{q}}{\alpha} \bar{F}(\bar{q})<0 .
\end{aligned}
$$

$$
\begin{aligned}
& \frac{\partial E\left[\pi_{M}^{1}\right]}{\partial \alpha} \\
& = \begin{cases}\left(\alpha \omega-c+K_{1}(1+r) f\left(F^{-1}\left(1-\frac{\alpha \omega}{p+s}\right)+\frac{B}{c}\right)\right) \frac{d q_{B}^{*}}{d \alpha}+\omega F^{-1}\left(1-\frac{\alpha \omega}{p+s}\right), & Q_{1}^{*}=q_{B}^{*}=F^{-1}\left(1-\frac{\alpha \omega}{p+s}\right) \\
\omega F^{-1}(1-\alpha)+K_{1}(1+r) f\left(\frac{B}{c}+q_{B}^{*}\right) \frac{d q_{B}^{*}}{d \alpha}, & Q_{1}^{*}=F^{-1}\left(1-\frac{c}{\omega}\right), q_{B}^{*}=F^{-1}(1-\alpha) \\
\frac{1}{c} \frac{\partial \bar{q}}{\partial \alpha}\left[\alpha \omega^{2} \bar{F}\left(\frac{\alpha \omega \bar{q}+B+K_{1}}{c}\right)\right]+\frac{\bar{q}}{c} \omega^{2} \bar{F}\left(\frac{\alpha \omega \bar{q}+B+K_{1}}{c}\right)+c\left(K_{1}(1+r) f\left(\bar{q}+\frac{B}{c}\right)\right), & Q_{1}^{*}=\frac{\left(\alpha \omega \bar{q}+B+K_{1}\right)}{c}, q_{B}^{*}=\bar{q},\end{cases}
\end{aligned}
$$

where $\bar{q}$ is the positive solution of (16).

Proof. (1) For $Q_{1}^{*}=q_{B}^{*}=F^{-1}(1-\alpha \omega /(p+s))$, from the conclusion of Proposition 1, we have

$$
\begin{aligned}
& \frac{\partial \pi_{M}^{1}}{\partial \alpha}=(\alpha \omega-c \\
& \left.\quad+K_{1}(1+r) f\left(F^{-1}\left(1-\frac{\alpha \omega}{p+s}\right)+\frac{B}{c}\right)\right) \frac{d q_{B}^{*}}{d \alpha} \\
& \quad+\omega F^{-1}\left(1-\frac{\alpha \omega}{p+s}\right)>0 .
\end{aligned}
$$

In summary, if the distribution of demand is IFR, $\partial E\left[\pi_{R}^{1}\right] / \partial \alpha<0$ holds, and $E\left[\pi_{R}^{1}\right]$ is a decreasing function with respect to $\alpha$.

Proposition 3. For IFR distributions of demand, if credit loan $K_{1}$ is a constant, then the manufacturer's profit $E\left[\pi_{M}^{1}\right]$ is an increasing function about $\alpha$ and can be given by 
In summary, if the distribution of demand is IFR, $\partial E\left[\pi_{M}^{1}\right] /$ $\partial \alpha>0$ holds. The manufacturer's profit $E\left[\pi_{M}^{1}\right]$ is an increasing function with respect to $\alpha$.

\section{Supply Chain Decision under PCFM}

Manufacturer with capital constraint also can select requesting credit loan directly from commercial bank with PCFM. After checking the relation between manufacturer and supplier, the commercial bank provides certain loan $K_{2}$ to the manufacturer who should repay the capital and interest $K_{2}(1+r)$ at the end of the selling season. To avoid default risk, sales income should be greater than the capital and interest to be repaid; that is, $K_{2}(1+r) \leq \omega Q_{2}$. At the beginning of selling season, the retailer orders products with quantity of $q=\min \left(X, Q_{2}\right)$ from the manufacturer at wholesale price $\omega$, where the manufacturer production volume is $Q_{2}$.

At the beginning of selling season, the retailer places purchase order with amount of $q_{2}=\min \left(X, Q_{2}\right)$ from the manufacturer according to its judgment on market demand and production capacity of the manufacturer. For $q_{2} \leq B / c$, the manufacturer could satisfy the retailer's order demand with its own capital; for $B / c<q_{2} \leq\left(B+K_{2}\right) / c$, the manufacturer could satisfy retailer's order demand through loan; for $\left(B+K_{2}\right) / c<q_{2}$, the order quantity of retailer exceeds the manufacturer's maximum production volume after financing. In this case, the retailer will be out of stock with unit cost $s$. Profit of the retailer can be given by

$$
\begin{aligned}
& \pi_{R}^{2} \\
& = \begin{cases}(p-\omega) X, & X<Q_{2} \leq \frac{B}{c} \\
(p-\omega) X, & \frac{B}{c}<X \leq Q_{2} \leq \frac{\left(B+K_{2}\right)}{c} \\
(p-\omega) Q_{2}-s\left(X-Q_{2}\right), & Q_{2}<\frac{\left(B+K_{2}\right)}{c}<X .\end{cases}
\end{aligned}
$$

The excepted profit of retailer under PCFM is as follows:

$$
\begin{aligned}
E\left[\pi_{R}^{2}\right]= & \int_{0}^{Q_{2}}[(p-\omega) X] f(x) d x \\
& +\int_{Q_{2}}^{+\infty}\left[(p-\omega) Q_{2}-s\left(X-Q_{2}\right)\right] f(x) d x \\
= & (p-\omega)\left(Q_{2}-\int_{0}^{Q_{2}} F(x) d x\right) \\
& -s \int_{Q_{2}}^{+\infty}\left(X-Q_{2}\right) f(x) d x .
\end{aligned}
$$

In initial production period, after receiving order from the retailer, decision sequence of the manufacturer is as follows: for $q_{2} \leq B / c$, the manufacturer could satisfy the retailer's order demand with its own capital and does not need financing; for $B / c<q_{2} \leq\left(B+K_{2}\right) / c$, the manufacturer could satisfy the retailer's order demand through loan; for $\left(B+K_{2}\right) / c<q_{2}$, the order quantity of retailer exceeds the maximum production volume of manufacturer after financing. Production volume of the manufacturer is $Q_{2}$.

(1) For $q_{2} \leq B / c$, the manufacturer does not need financing; that is, it could satisfy the retailer's order demand with its own capital. Manufacturer's profit is $\pi_{M}^{2}=\omega \min \left(X, Q_{2}\right)-$ $c Q_{2}$.

(2) For $B / c<q_{2} \leq\left(B+K_{2}\right) / c$, the manufacturer needs loan from bank and should repay the capital and interest $K_{2}(1+r)$ at the end of sales season. Manufacturer's profit is $\pi_{M}^{2}=\omega \min \left(X, Q_{2}\right)-K_{2}(1+r)-c Q_{2}$.

(3) For $\left(B+K_{2}\right) / c<q_{2}$, the order quantity exceeds the manufacturer's maximum production volume with loan. Manufacturer's profit is $\pi_{M}^{2}=\left(\omega-c Q_{2}\right)-K_{2}(1+r)$.

Therefore, manufacturer's profit under PCFM is as follows:

$$
\pi_{M}^{2}= \begin{cases}\omega X-c Q, & X<Q \leq \frac{B}{c} \\ \frac{\omega B}{c}+\omega\left(X-\frac{B}{c}\right)-c Q-K_{2}(1+r), & \frac{B}{c}<X \leq Q \leq \frac{\left(B+K_{2}\right)}{c} \\ (\omega-c) Q-K_{2}(1+r), & Q<\frac{\left(B+K_{2}\right)}{c}<X .\end{cases}
$$

Decision model of manufacturer is given by

$$
\begin{array}{ll} 
& E\left[\pi_{M}^{2}\right] \\
= & (\omega-c) Q_{2}-\left(1-F\left(\frac{B}{c}\right)\right) K_{2}(1+r) \\
& -\omega \int_{0}^{Q_{2}} F(x) d x \\
\text { s.t. } \quad & \frac{K_{2}(1+r)}{\omega} \leq Q_{2} \leq \frac{B+K_{2}}{c} .
\end{array}
$$

Owning to the fact that $\partial^{2} E\left[\pi_{M}^{2}\right] / \partial Q_{2}{ }^{2}=-\omega f\left(Q_{2}\right)<0$ and the constraint conditions are linear constraint conditions of $Q_{2}$, (32) is a nonlinear convex programming problem about $Q_{2}$. According to Kuhn-Tucker conditions, the manufacturer's optimal production volume $Q_{2}^{*}$ is

$$
= \begin{cases}\frac{K_{2}(1+r)}{\omega}, & F^{-1}\left(1-\frac{c}{\omega}\right)<\frac{K_{2}(1+r)}{\omega} \\ F^{-1}\left(1-\frac{c}{\omega}\right), & \frac{K_{2}(1+r)}{\omega} \leq F^{-1}\left(1-\frac{c}{\omega}\right) \leq \frac{B+K_{2}}{c} \\ \frac{B+K_{2}}{c}, & \frac{B+K_{2}}{c}<F^{-1}\left(1-\frac{c}{\omega}\right) .\end{cases}
$$


Proposition 4. Under PCFM, if the manufacturer carries out production according to $Q_{2}^{*}$, the optimal loan amount is as follows:

$$
\begin{array}{ll}
K_{2}^{*} & \begin{cases}\frac{\omega}{1+r} F^{-1}\left(F\left(\frac{B}{c}\right)-\frac{c}{\omega}\right), & Q_{2}^{*}=\frac{K_{2}(1+r)}{\omega} \\
c F^{-1}\left(1-\frac{c}{\omega}\right)-B, & Q_{2}^{*}=F^{-1}\left(1-\frac{c}{\omega}\right) .\end{cases}
\end{array}
$$

Proof. (1) For $Q_{2}^{*}=K_{2}(1+r) / \omega, \partial^{2} E\left[\pi_{M}^{2}\right] / \partial K_{2}^{2}=-(1+$ $r) f\left(K_{2}(1+r) / \omega\right)((1+r) / \omega)<0$ holds. From the first-order optimality condition,

$$
\begin{aligned}
\frac{\partial E\left[\pi_{M}^{2}\right]}{\partial K_{2}}= & (\omega-c) \frac{(1+r)}{\omega}-\left(1-F\left(\frac{B}{c}\right)\right)(1+r) \\
& -(1+r) F\left(\frac{K_{2}(1+r)}{\omega}\right)=0 .
\end{aligned}
$$

We have

$$
F^{-1}\left(1-\frac{c}{\omega}\right)<F^{-1}\left(F\left(\frac{B}{c}\right)-\frac{c}{\omega}\right) \Longrightarrow F\left(\frac{B}{c}\right)<1
$$

and $K_{2}^{*}=(\omega /(1+r)) F^{-1}(F(B / c)-c / \omega)$.

(2) For $Q_{2}^{*}=F^{-1}(1-c / \omega), \partial^{2} E\left[\pi_{M}^{2}\right] / \partial K_{2}{ }^{2}=-(1-$ $F(B / c))(1+r)<0$ holds. From the first-order optimum condition,

$$
\frac{\partial E\left[\pi_{M}^{2}\right]}{\partial K_{2}}=-\left(1-F\left(\frac{B}{c}\right)\right)(1+r)<0 .
$$

So, the manufacture should try to satisfy the production demand with loan from commercial bank, and the optimal loan amount is $K_{2}^{*}=c Q^{*}-B=c F^{-1}(1-c / \omega)-B$.

(3) For $Q_{2}^{*}=\left(B+K_{2}\right) / c, \partial^{2} E\left[\pi_{M}^{2}\right] / \partial K_{2}{ }^{2}=-\left(\omega / c^{2}\right) f((B+$ $\left.\left.K_{2}\right) / c\right)<0$ is obtained. According to the first-order optimum condition $\partial E\left[\pi_{M}^{2}\right] / \partial K_{2}=(\omega-c) / c-(1-F(B / c))(1+r)-$ $(\omega / c) F\left(\left(B+K_{2}\right) / c\right)=0$, the optimal loan amount should not exist in this case, because of $F^{-1}[(\omega-c) / \omega-(c / \omega)(1-$ $F(B / c)(1+r))]<F^{-1}(1-c / \omega)$.

\section{Comparison of Supply Chain Performances}

Considering the goal of maximizing profit of the whole supply chain and the profits under the conditions of no capital constraint, RPFM and PCFM are compared.

Under RPFM, $Q_{1}^{*}$ is the maximum value point and $Q_{1}^{*}>$ $Q_{N}$. For $q_{B} \leq F^{-1}(1-c / \omega) \leq Q_{\max }$, the manufacturer does not need loan: that is, $K_{1}^{*}=0$. For $Q_{\max } \leq F^{-1}(1-c / \omega) \leq$ $\left(L+B+K_{1}\right) / c$, commercial bank loan can be expressed as $K_{1}^{*}=c\left(F^{-1}(1-c / \omega)-F^{-1}(1-\alpha)-B / c\right)$.

Under PFCM, the maximum production capacity of manufacturer is $Q_{2}^{*}=F^{-1}(1-c / \omega)$, and the loan from commercial bank is $K_{2}^{*}=c F^{-1}(1-c / \omega)-B$. By comparing profits of the supply chain, we can get the following conclusions.
Proposition 5. In case of capital constraint, under RPFM, we have $Q_{1}^{*}>Q_{N}$. And for $q_{B} \leq F^{-1}(1-c / \omega) \leq Q_{\max }$, we have $E\left(\pi_{T, Q}^{2}\right)>E\left(\pi_{T}^{N}\right)$. Under PCFM, similarly, $Q_{2}^{*}>Q_{N}$. Besides, for $r<\left(1 / K_{2}^{*}\right)\left[(c(p-\omega) /(\omega+s))\left(Q_{2}^{*}-Q_{N}\right)-K_{2}^{*}\right]$, we have $E\left(\pi_{T, Q}^{2}\right)>E\left(\pi_{T}^{N}\right)$; for $Q_{1}^{*}=Q_{2}^{*}=F^{-1}(1-c / \omega)$, RPFM and PCFM have the same optimal production volume and $E\left(\pi_{T, Q}^{2}\right)<E\left(\pi_{T, Q}^{1}\right)$.

Proof. Firstly, if the manufacturer adopts RPFM, from the assumption, the manufacturer's optimal production volume $Q_{1}^{*}=F^{-1}(1-c / \omega)>Q_{N}=F^{-1}(1-\omega /(p+s))$ holds.

(1) For $q_{B} \leq F^{-1}(1-c / \omega) \leq Q_{\max }$, we have

$$
\begin{aligned}
& E\left(\pi_{T, Q}^{1}\right)-E\left(\pi_{T}^{N}\right) \\
& \quad=(p-c+s)\left(Q_{1}^{*}-Q_{N}\right)-(p+s) \int_{Q_{N}}^{Q_{1}^{*}} F(x) d x \\
& > \\
& \quad=\frac{\left.c(p+s-\omega)-(p+s) F\left(Q_{1}^{*}\right)\right]\left(Q_{1}^{*}-Q_{N}\right)}{\omega}\left(Q_{1}^{*}-Q_{N}\right)>0 .
\end{aligned}
$$

Therefore, it is easy to observe $E\left(\pi_{T, Q}^{1}\right)>E\left(\pi_{T}^{N}\right)$.

(2) For $Q_{\max } \leq F^{-1}(1-c / \omega) \leq(L+B+K) / c$, we have

$$
\begin{aligned}
E\left(\pi_{T, Q}^{1}\right)-E\left(\pi_{T}^{N}\right) & \\
= & (p-c+s)\left(Q_{1}^{*}-Q_{N}\right)-(p+s) \int_{Q_{N}}^{Q_{1}^{*}} F(x) d x \\
& -K_{1}^{*}(1+r) \\
> & {\left[(p-c+s)-(p+s) F\left(Q_{1}^{*}\right)\right]\left(Q_{1}^{*}-Q_{N}\right) } \\
& -K_{1}^{*}(1+r) \\
= & \frac{c(p+s-\omega)}{\omega}\left(Q_{1}^{*}-Q_{N}\right)-K_{1}^{*}(1+r) .
\end{aligned}
$$

Therefore, for $r<\left(1 / K_{1}^{*}\right)\left[(c(p+s-\omega) / \omega)\left(Q_{1}^{*}-Q_{N}\right)-K_{1}^{*}\right]$, $E\left(\pi_{T, Q}^{1}\right)>E\left(\pi_{T}^{N}\right)$ holds.

In addition, the manufacturer's maximum production volume is $Q_{2}^{*}=F^{-1}(1-c / \omega)$ under PCFM. According to the assumption, $Q_{2}^{*}=F^{-1}(1-c / \omega)>Q_{N}$, and the loan amount is $K_{2}^{*}=c F^{-1}(1-c / \omega)-B$. We deduce

$$
\begin{aligned}
E\left(\pi_{T, Q}^{2}\right)-E\left(\pi_{T}^{N}\right) & \\
= & (p-c+s)\left(Q_{2}^{*}-Q_{N}\right)-(p+s) \int_{Q_{N}}^{Q_{2}^{*}} F(x) d x \\
& \quad-K_{2}^{*}(1+r) \\
> & {\left[(p-c+s)-(p+s) F\left(Q_{2}^{*}\right)\right]\left(Q_{2}^{*}-Q_{N}\right) } \\
& -K_{2}^{*}(1+r) \\
= & \frac{c(p+s-\omega)}{\omega}\left(Q_{2}^{*}-Q_{N}\right)-K_{2}^{*}(1+r) .
\end{aligned}
$$


For $r<\left(1 / K_{2}^{*}\right)\left[(c(p+s-\omega) / \omega)\left(Q_{2}^{*}-Q_{N}\right)-K_{2}^{*}\right], E\left(\pi_{T, Q}^{2}\right)>$ $E\left(\pi_{T}^{N}\right)$ holds.

Furthermore, we can get the result of the supply chain profits under two financing modes as follows.

(1) For $q_{B} \leq F^{-1}(1-c / \omega) \leq Q_{\max }$,

$$
E\left(\pi_{T, Q}^{2}\right)-E\left(\pi_{T, Q}^{1}\right)=-K_{2}^{*}(1+r)<0,
$$

and we get $E\left(\pi_{T, Q}^{2}\right)<E\left(\pi_{T, Q}^{1}\right)$.

(2) For $Q_{\max } \leq F^{-1}(1-c / \omega) \leq(L+B+K) / c$,

$$
\begin{aligned}
E\left(\pi_{T, \mathrm{Q}}^{2}\right)-E\left(\pi_{T, \mathrm{Q}}^{1}\right) & =\left(K_{1}^{*}-K_{2}^{*}\right)(1+r) \\
& =-c F^{-1}(1-\alpha)(1+r)<0 .
\end{aligned}
$$

So, $E\left(\pi_{T, Q}^{2}\right)<E\left(\pi_{T, Q}^{1}\right)$ holds.

According to the conclusion of Proposition 5, both the two financing modes can create new value and profit for the supply chain under capital constraint and can achieve the optimal production when there is no capital constraint. If the secondary financing is needed when their own capital could not satisfy the second-order demand, the manufactures need the second financing, and the loan interest rate meets certain requirements, the RPFM can increase production volume of the manufacturer and increase profit of the entire supply chain; the corresponding conclusion can also be reached under PCFM. By comparing these two financing modes, the whole supply chain performance is better than that with financing from a commercial bank by PCFM. Therefore, the RPFM should be adopted.

\section{Numerical Example and Analysis}

6.1. Parameter Setting. To ensure consistency of the study, it is assumed that the market demand on certain product of the manufacturer satisfies the uniform distribution in $[0,800]$, the unit market sale price $p=100$, the unit wholesale price $\omega=60$, the unit stock out cost $s=40$, manufacturer's unit production cost $c=20$, loan interest rate of commercial bank $r=0.045$, manufacturer's own capital amount $B=6000$, and production volume with its own capital $Q_{0}=300$.

6.2. Numerical Example. When there is no capital constraint and the manufacturer carries out optimal production according to classic "newsvendor" model, the optimal production volume and expected profits of manufacturer, retailer, and the whole supply chain are calculated as follows: $Q_{N}=457$, $E\left[\pi_{R}^{N}\right]=2286, E\left[\pi_{M}^{N}\right]=18280$, and $E\left[\pi_{T}^{N}\right]=20566$. Under capital constraint, if the manufacturer produces with its own capital, expected profits of manufacturer, retailer, and the entire supply chain are $E\left[\pi_{R}^{C}\right]=125, E\left[\pi_{M}^{C}\right]=12000$, and $E\left[\pi_{T}^{C}\right]=12125$, respectively. Obviously, in case of capital constraint, the manufacturer, retailer, and the entire supply chain cannot achieve the expected optimal profits.

Under the RPFM, the manufacturer's optimal production volume and retailer's order quantity are related to the discount coefficient. By verifying Formula (17), after secondary financing, the manufacturer could realize optimal production and not all the loan from the secondary financing is used in production.

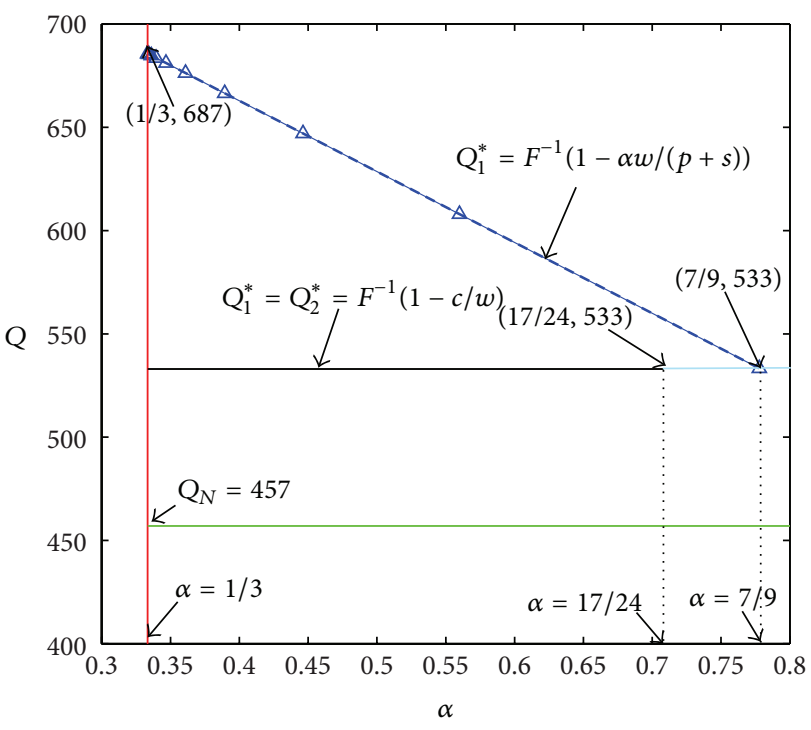

FIGURE 2: Optimal production volumes of the manufacturer under the two financing modes.

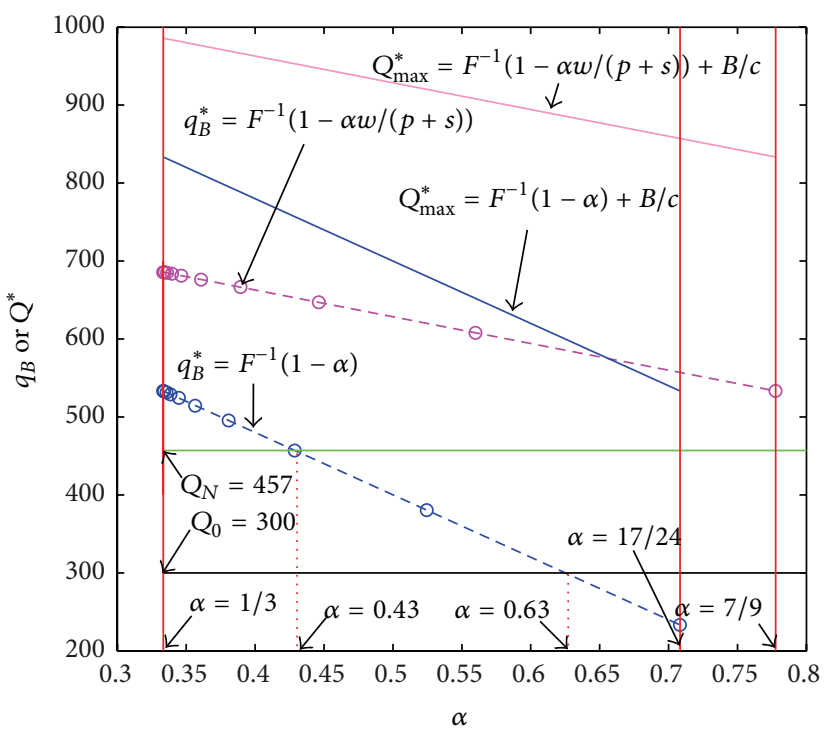

FIGURE 3: Preorder quantity of retailer under RPFM.

Under the PCFM, from (33) and (34), $Q_{2}^{*}=F^{-1}(1-c / \omega)$ is verified satisfying the conditions; in this case, we have $Q_{2}^{*}=533$. Figure 2 shows the optimal production volumes of manufacturer under the two financing modes.

From Figure 2, under the RPFM, the optimal production volume $Q_{1}^{*}$ decreases with increase of discount coefficient $\alpha$, presenting negative correlation: that is, high discount price required by the retailer will lead to low wholesale price and high optimal production volume of the manufacturer. In addition, the manufacturer can achieve the optimal production volume under both financing modes.

Under the RPFM, the relation between $q_{B}^{*}$ and the discount price $\alpha$ is illustrated in Figure 3, so as to show the influence of discount coefficient $\alpha$ on retailer's order quantity. 


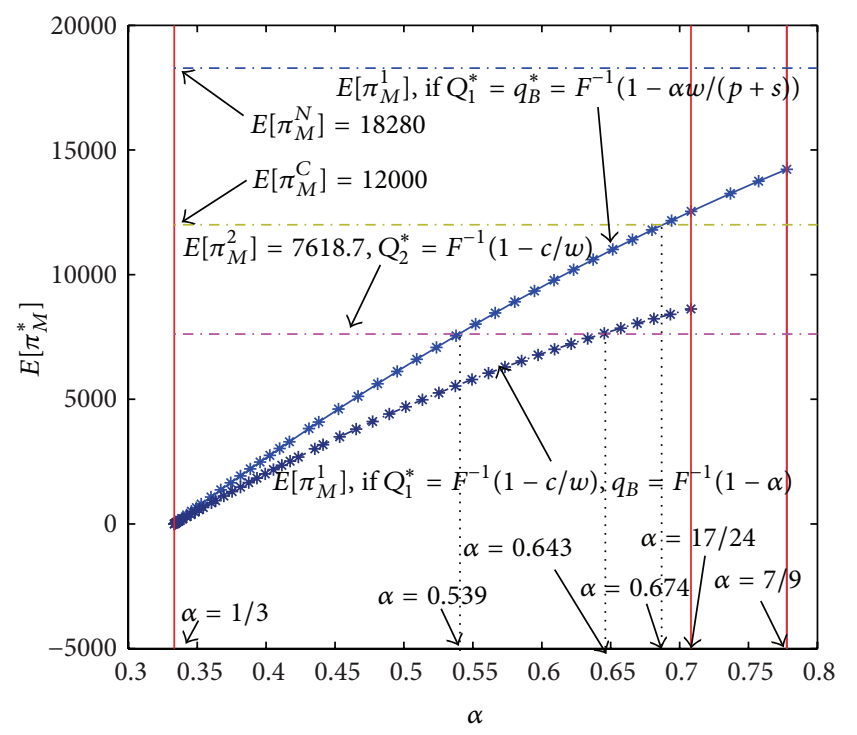

FIGURE 4: Comparison of manufacturer's expected profits under two financing modes.

From Figure 3, under the RPFM, $q_{B}^{*}$ is negative correlation with the discount coefficient $\alpha$. Besides, if the manufacturer could satisfy retailer's secondary order with own capital, for $0.43<\alpha<0.63$, the production volume with its own capital is less than retailer's order quantity. To increase production and sales volume, the manufacturer should adopt RPFM. For $0.63<\alpha<17 / 24$, the production volume with the manufacturer's own capital is more than retailer's order quantity under RPFM. With large bargaining space, the manufacturer may choose whether to accept preorder request of the retailer in discount price.

Changes in expected optimal profit of manufacturer under two financing modes are shown in Figure 4.

From Figure 4, the expected profits of the manufacturer under the both modes are lower than that under classic "newsvendor" model, and the profit under RPFM is also lower than that with the manufacture's own capital. In addition, with different optimal production volumes, preorder volumes, and discount coefficients, the manufacturer will choose different financing modes.

Figure 5 shows expected profits of retailer under two modes.

From Figure 5, the retailer's profits under both financing modes are higher than that under classic "newsvendor" model and the manufacturer's optimal profit with own capital. No matter which financing mode is then adopted by the manufacturer, the retailer's profits can always increase. Moreover, under the RPFM, retailer's expected profit will decrease with increase of discount coefficient.

The optimal expected profits of supply under the two financing modes are compared (as shown in Figure 6).

Figure 6 shows that, under the RPFM, profits of the supply chain are more than those under classic "newsvendor" model and the PCFM. For $1 / 3<\alpha<7 / 9$, profits of the supply chain can reach the maximum value and will decrease with increase of discount coefficient $\alpha$, which also indicates

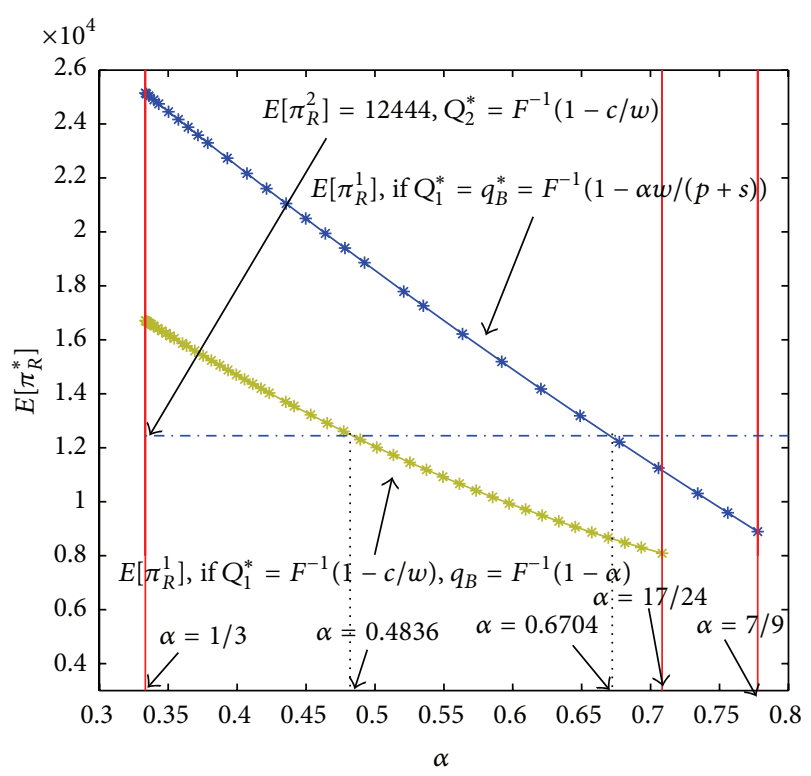

FIGURE 5: Comparison of the retailer's expected profits under the two financing modes.

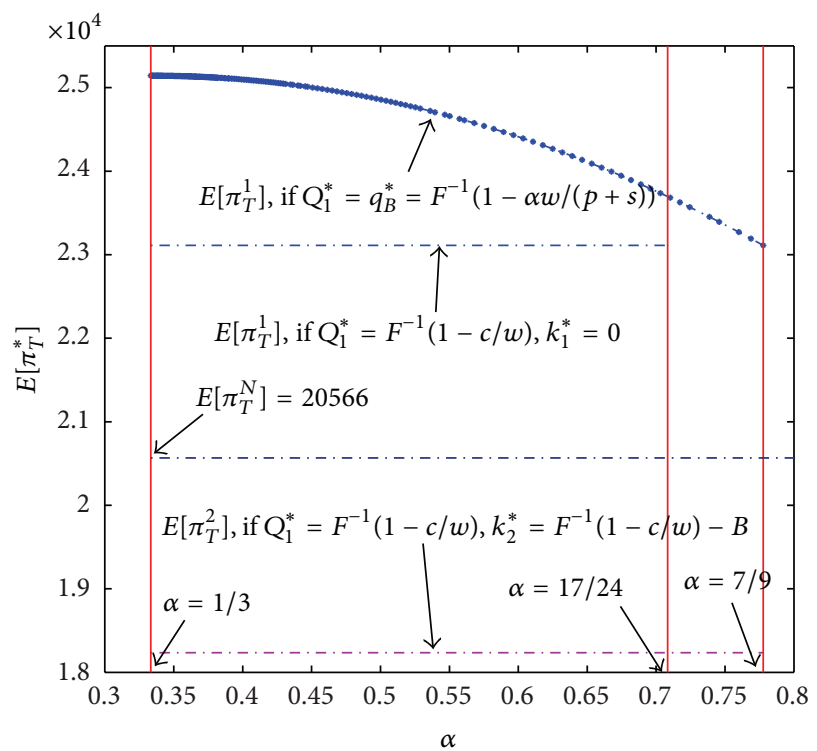

FIGURE 6: Comparison of expected profits of the entire supply chain.

that the larger discount will lead to higher profit of the supply chain. It is a remarkable fact that, if the manufacturer adopts PCFM, profit of the supply chain will be less than that under classic "newsvendor" model, which, according to Proposition 5, is mainly because of the failure in meeting boundary conditions of interest rate.

\section{Conclusions}

The manufacturer will address the capital constraint during production and operation through financing in order to realize optimal production and maximize the profit. The manufacturer with capital constraint could finance through 
the retailer's prepayment financing mode (RPFM) and the procurement contract financing mode (PCFM). Aiming at these two financing modes, in this paper, the optimal production and financing decision problems of the manufacturer are studied; meanwhile, under the RPFM, the optimal order quantity is studied based on the discount coefficient; at last, under both financing modes, we compare expected profits of the manufacturer, retailer, and the entire supply chain through the numerical simulation.

Through our analysis, the result shows that when the discount coefficient meets certain requirements, profits of the manufacturer, retailer, and the entire supply chain can all increase and will be generally superior to those under the PCFM. The optimal production volume of the manufacturer is greater than that with its own capital under the PCFM. In addition, due to the influence of interest rate and selection of initial simulation date, in this case, expected profits of the manufacturer and the entire supply chain are less than those with the manufacturer's own capital and under classic "newsvendor" model.

In addition, our analytical and numerical results include some theoretical and managerial implications in terms of supply chain financial management and optimization. First, the retailer, manufacturer, and the entire supply chain are always more profitable and the manufacturer's optimal production volume can be increased by financing. Hence, it proved that the financing service can create new value and impact on enterprise's operational decision. Second, from the entire supply chain perspective, the bank's loan interest rate plays a key role and influences the manufacturer's financing decision-making and profit level. Moreover, the profit level under RPFM is higher than PCFM; it reveals why manufacturer prefers to select inner financing mode such as RPFM compared to external finance mode from a commercial bank.

Finally, there are some limitations and possible directions can be addressed in future research. First, our works mainly focus on the supply chain financing and optimal decision; however, how to use contracts to coordinate the capital-constrained supply chain under RPFM and PCFM will be another research problem in the future. Second, the commercial bank's risk control and product residual value should be taken into account. Third, actually, under the condition of asymmetric information assumption, the retailer and manufacturer have game relationship. So, how to select the financing mode and make decision is needed to give the further discussion.

\section{Notations}

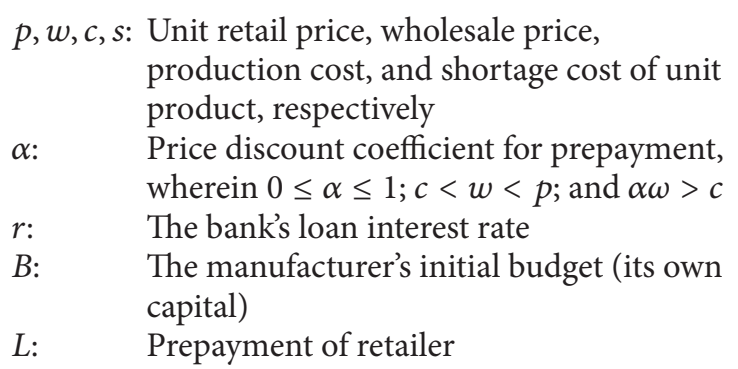

$Q_{0}: \quad$ Manufacturer's production volume with

initial budget (its own capital)

$Q_{\max }: \quad$ The maximum production of

manufacturer under prepayment

$K_{1}, K_{2}$ : Loan amount from commercial bank

$Q_{N}, Q_{1}, Q_{2}: \quad$ The manufacturer's production volume, respectively, under "newsvendor" mode, RPFM, and PCFM

$Q_{1}^{*}, Q_{2}^{*}:$

The manufacturer's optimal production volume, respectively, under RPFM and PCFM

$\pi_{M}^{N}, \pi_{R}^{N}, \pi_{T}^{N}: \quad$ Profits of the manufacturer, retailer, and the entire supply chain with no capital constraint

$\pi_{M}^{C}, \pi_{R}^{C}, \pi_{T}^{C}$ Profits of the manufacturer, retailer, and the entire supply chain with its own capital

$\pi_{M}^{1}, \pi_{M}^{2}, \pi_{R}^{1}, \pi_{R}^{2}$, Profits of the manufacturer, retailer, and $\pi_{T, Q}^{1}, \pi_{T, Q}^{2}$ the entire supply chain under RPFM and PCFM

$X:$

Random demand of market consumption. The probability density function and distribution function are $f(x)$ and $F(x)$, respectively, wherein, $F(x)$ satisfies the failure distribution IFDR characteristic of monotone increasing.

\section{Competing Interests}

The authors declare that there is no conflict of interests regarding the publication of this paper.

\section{Acknowledgments}

This work is supported by the National Natural Science Foundation of China (no. 71573072).

\section{References}

[1] F. Modigliani and M. Miller, "The cost of capital, corporation finance and the theory of investment," American Economic Review, vol. 48, no. 3, pp. 261-297, 1958.

[2] M. Harris and A. Raviv, "The theory of capital structure," Journal of Finance, vol. 46, no. 1, pp. 297-355, 1991.

[3] R. Levaggi, "Optimal procurement contracts under a binding budget constraint," Public Choice, vol. 101, no. 1-2, pp. 23-37, 1999.

[4] J. Birge $\mathrm{R}$ and $\mathrm{X}$. Xu, "Joint production and financing decisions: modeling and analysis," Tech. Rep., Northwestern University, Evanston, Ill, USA, 2004.

[5] R. Cadentey and X. F. Chen, "Financing service and supply chain contracting," Working Paper Series, Stern School of Business in New York University, 2007.

[6] D. Seifert, R. W. Seifert, and M. Protopappa-Sieke, "A review of trade credit literature: opportunities for research in operations," European Journal of Operational Research, vol. 231, no. 2, pp. 245-256, 2013. 
[7] R. Fisman and I. Love, "Trade credit, financial intermediary development, and industry growth," Journal of Finance, vol. 58, no. 1, pp. 353-374, 2003.

[8] Y. Ge and J. Qiu, "Financial development, bank discrimination and trade credit," Journal of Banking \& Finance, vol. 31, no. 2, pp. 513-530, 2007.

[9] P. L. Abad and C. K. Jaggi, "A joint approach for setting unit price and the length of the credit period for a seller when end demand is price sensitive," International Journal of Production Economics, vol. 83, no. 2, pp. 115-122, 2003.

[10] M. Protopappa-Sieke and R. W. Seifert, "Interrelating operational and financial performance measurements in inventory control," European Journal of Operational Research, vol. 204, no. 3, pp. 439-448, 2010.

[11] Y. Wang, Y. H. Shao, and J. Q. Ou, "The research on trade credit short-term financing in a capital-constrained supply chain," in Proceedings of the International Conference on Management Science and Management Innovation, pp. 491-505, Atlantis Press, 2014.

[12] K.-J. Chung and Y.-F. Huang, "The optimal cycle time for EPQ inventory model under permissible delay in payments," International Journal of Production Economics, vol. 84, no. 3, pp. 307-318, 2003.

[13] C. H. Lee and B.-D. Rhee, "Coordination contracts in the presence of positive inventory financing costs," International Journal of Production Economics, vol. 124, no. 2, pp. 331-339, 2010.

[14] X. Chen and A. Wang, "Trade credit contract with limited liability in the supply chain with budget constraints," Annals of Operations Research, vol. 196, no. 1, pp. 153-165, 2012.

[15] J. A. Buzacott and R. Q. Zhang, "Inventory management with asset-based financing," Management Science, vol. 50, no. 9, pp. 1274-1292, 2004.

[16] N. Yan and B. Sun, "Coordinating loan strategies for supply chain financing with limited credit," OR Spectrum, vol. 35, no. 4, pp. 1039-1058, 2013.

[17] N. N. Yan and B. W. Sun, "Comparative analysis of supply chain financing strategies between different financing modes," Journal of Industrial and Management Optimization, vol. 11, no. 4, pp. 1073-1087, 2015.

[18] X. H. Yi and Z. F. Zhou, "Pricing decisions on inventory financing of the banks with core enterprises' buy-back guarantee," Systems Engineering, vol. 29, no. 1, pp. 38-44, 2011.

[19] Y.-G. Zhang and X.-W. Tang, "Manufacturer's optimal policies in supply chain finance," System Engineering-Theory and Practice, vol. 33, no. 6, pp. 1434-1440, 2013.

[20] Q.-H. Lu, L.-F. Zeng, and X. Bao, "Supply chain financing with purchase-order based on Stackelberg game," Control and Decision, vol. 29, no. 10, pp. 1907-1913, 2014.

[21] L. W. Wang and J. W. Luo, "Advance payment financing strategies of supply chains based on price discount," Journal of Management Science in China, vol. 17, no. 11, pp. 20-31, 2014.

[22] J. Zhou and H. Groenevelt, "Impacts of financial collaboration in a three-party supply chain," Working Paper, The Simon School, University of Rochester, 2008.

[23] B. Jing, X. Chen, and G. G. Cai, "Equilibrium financing in a distribution channel with capital constraint," Production and Operations Management, vol. 21, no. 6, pp. 1090-1101, 2012.

[24] D. Fabbri and A. M. C. Menichini, "Trade credit, collateral liquidation, and borrowing constraints," Journal of Financial Economics, vol. 96, no. 3, pp. 413-432, 2010.
[25] R. Caldentey and X. F. Chen, "The role of financial services in procurement contracts," in The Handbook of Integrated Risk Management in Global Supply Chains, John Wiley \& Sons, New York, NY, USA, 2011.

[26] P. Kouvelis and W. Zhao, "Financing the newsvendor: supplier vs. bank, and the structure of optimal trade credit contracts," Operations Research, vol. 60, no. 3, pp. 566-580, 2012.

[27] X. Chen, "A model of trade credit in a capital-constrained distribution channel," International Journal of Production Economics, vol. 159, pp. 347-357, 2015.

[28] N. Yan, B. Sun, H. Zhang, and C. Liu, "A partial credit guarantee contract in a capital-constrained supply chain: financing equilibrium and coordinating strategy," International Journal of Production Economics, vol. 173, pp. 122-133, 2016.

[29] Y. Wang, X. Sun, and F. Meng, "On the conditional and partial trade credit policy with capital constraints: A Stackelberg Model," Applied Mathematical Modelling, vol. 40, no. 1, pp. 1-18, 2016.

[30] S. Q. Zeng and J. W. Luo, "Incentives mechanism for supply chain coordination with trade credit based on quantity discount," Journal of Systems and Management, vol. 24, no. 1, pp. 85-90, 2015.

[31] W. L. Wang and J. W. Luo, "Strategies for financing suppliers based on Retailers' prepayment and loan guarantee," Journal of Industrial Engineering and Engineering Management, vol. 27, no. 1, pp. 178-184, 2013.

[32] J. Z. Zhan, X. Z. Zhou, and Y. D. Gong, "Optimal financing and production decision in production capital constrained supply chain," Journal of Systems Engineering, vol. 30, no. 2, pp. 190200, 2015.

[33] X. Xiao and J. W. Luo, "Financing strategies for capital constrained manufacturer in the dual-channel supply chain," Journal of Systems and Management, vol. 25, no. 1, pp. 121-128, 2016. 


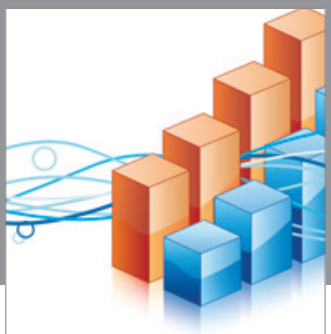

Advances in

Operations Research

vatem alat4

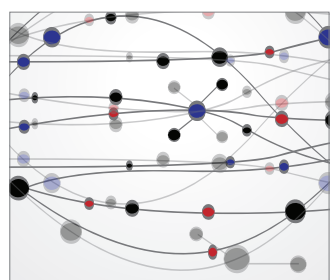

\section{The Scientific} World Journal
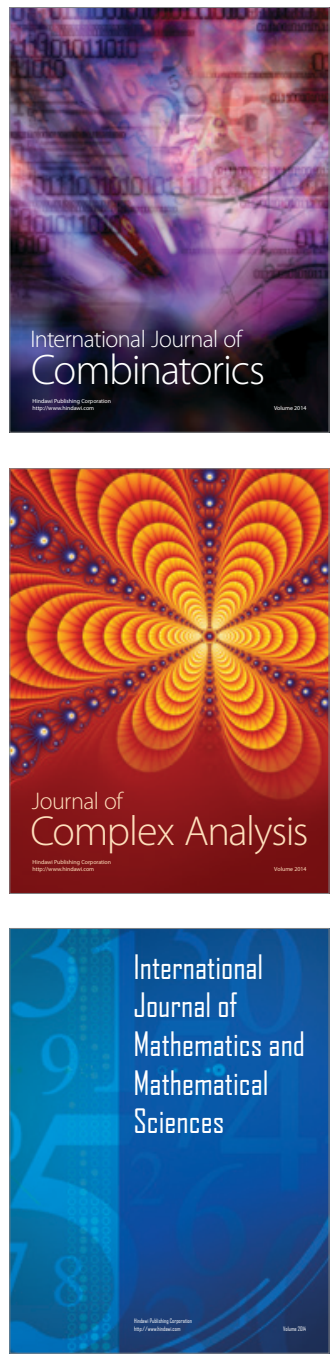
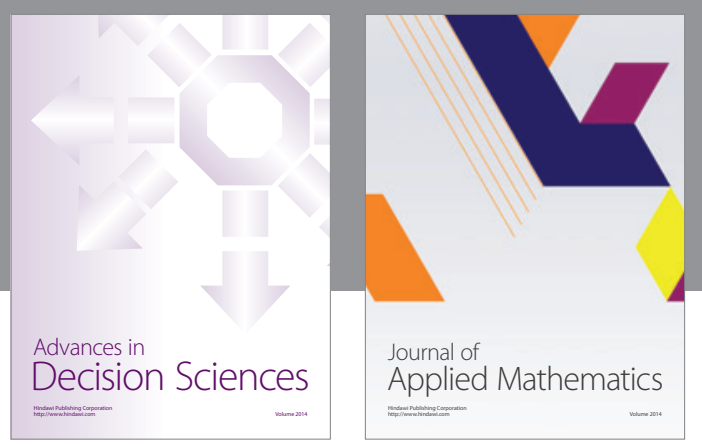

Algebra

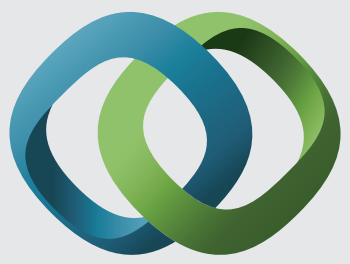

\section{Hindawi}

Submit your manuscripts at

http://www.hindawi.com
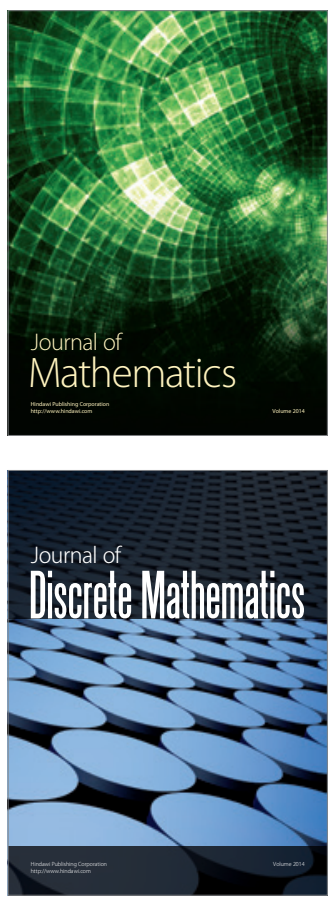

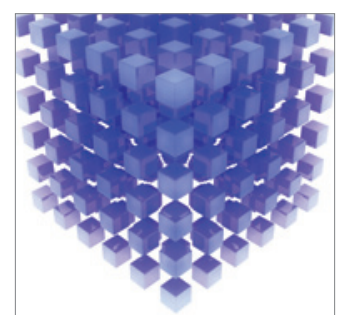

Mathematical Problems in Engineering
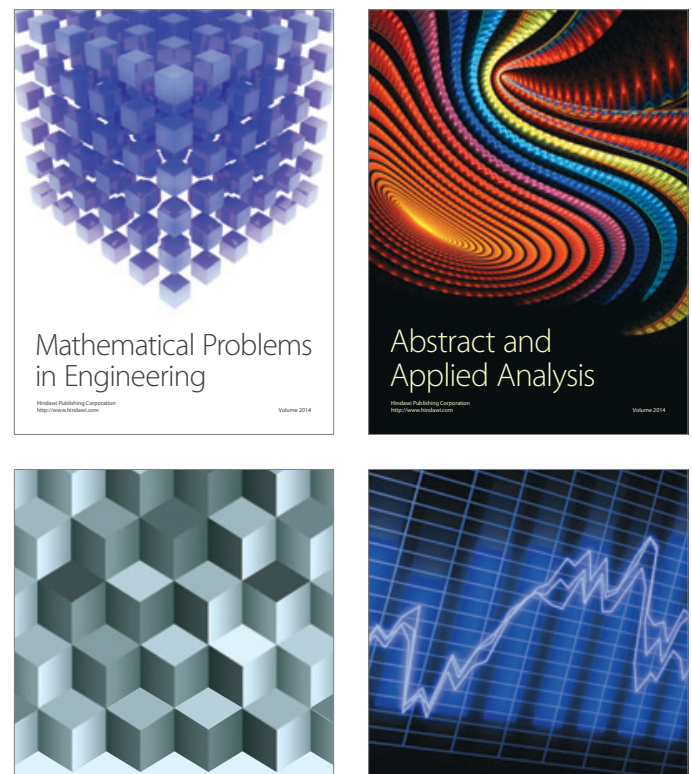

Journal of

Function Spaces

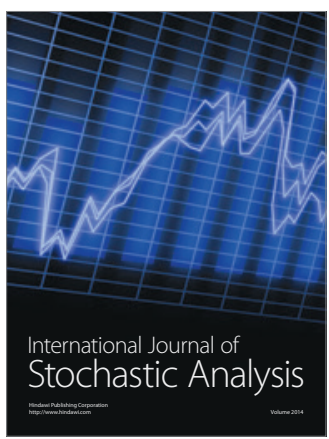

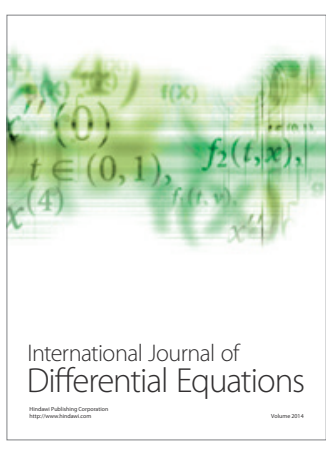
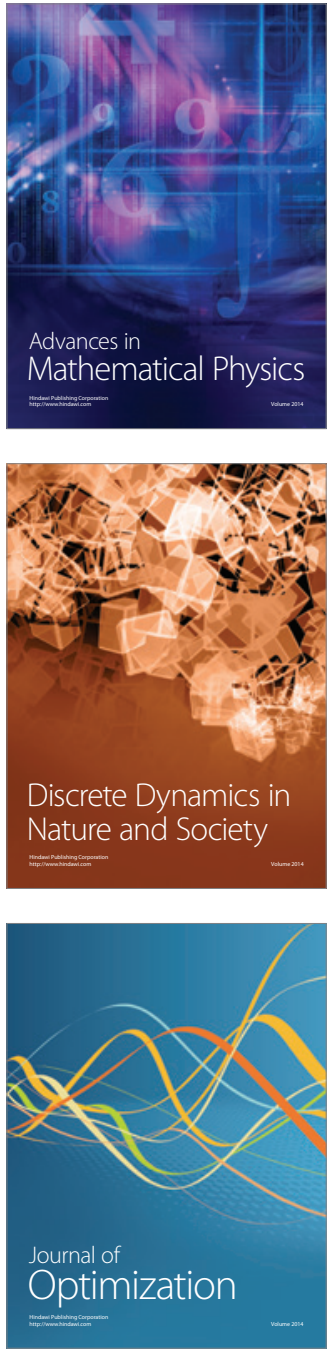